\title{
Numerical analysis of shallow foundations on geogrid reinforced soil
}

\author{
Mohamed G. Arab ${ }^{1,2}$, Maher Omar ${ }^{1}$ and Ali Tahmaz \\ ${ }^{1}$ Civil \& Environmental Engineering Department, University of Sharjah, 27272 Sharjah, UAE \\ ${ }^{2}$ Structural Engineering Department, Mansoura University, 27272 Sharjah, UAE
}

\begin{abstract}
Geogrids have been increasingly used as soil improvement technique over the past decade. This increasing trend is attributed to its ease of application and low cost compared to other improvement techniques. This paper provides a review of the published results related to the ultimate and allowable bearing capacities of shallow foundations on geo-grid-reinforced homogeneous sand soil. A numerical analysis is also conducted to investigate soil-geogrid interaction considering several critical parameters that affect the overall behavior of geogrid-reinforced soil. The critical parameters such as the width and length of geogrid layers, spacing between the reinforcement layers, and the depth of reinforcement and geosynthetic stiffness have been investigated.
\end{abstract}

\section{Introduction}

There are several geogrid-reinforcement techniques that gained wide popularity in the recent years for its proven performance, ease of installation and low cost compared with other improvement techniques. Mechanically stabilized earth technology for example is now well established in the heavy construction industry as a reliable method in the construction of structures such as retaining walls, embankments over soft soil, and steep slopes.

The first systematic study using mechanically stabilized earth to improve the bearing capacity of shallow foundations was reported by Binquet and Lee [1,2]. In their study, laboratory model tests were used to develop bearing capacity relationships for a strip foundation supported by sand reinforced with metallic strips (aluminum foil).

Since the original work by Binquet and Lee, several laboratory model test studies have been published relating to the improvement of the load-bearing capacity of shallow foundations supported by sand reinforced with various materials such as geogrids [3, 4], geotextiles [5], rope fibers [6], metal strips and metal bars [7-12].

Over the last decade, the use of geogrids for soil reinforcement has increased greatly, primarily because geogrids are dimensionally stable and combine features such as high tensile modulus (low strain at high load), open grid structure, positive shear connection characteristics, light weight, and long service life. 
This paper summarizes the important results of the existing studies on the load-bearing capacity of shallow foundations on geogrid-reinforced soil. Most of the results presently available have been obtained primarily from small-scale laboratory model tests. Moreover, a numerical study is conducted and results are presented in this paper. The numerical study shows some fundamental aspects of the behaviour of the geogrid reinforced sand. Different parameters that affect the behaviour of the geogrid reinforced sand is discussed.

\section{Failure mechanisms in geogrid reinforced soil at ultimate load}

Several researchers have studied the different geometrical parameters effect on the behaviour of the reinforced soils in a non-dimensional form (Figure 1a). These parameters are the following: a) location of the top layer of reinforcement measured from the bottom of the foundation, $u$; b) the depth of reinforcement, $d$

$$
d=u+(N-1) h
$$

where $N$ is the number of reinforcement layers and $\mathrm{h}$ is the vertical distance between two consecutive reinforcement layers;

c) width of each reinforcement layer, b; and d) length of each reinforcement layer, $l$.

The enhancement in bearing capacity due to soil reinforcement is generally expressed in terms of a non-dimensional parameter called bearing capacity ratio, BCR. The bearing capacity ratio can be expressed either in the form of ultimate bearing capacity or allowable bearing capacity at a given settlement level of the foundation [13]. Figure 1b shows typical load-settlement curves of a foundation over soil with and with-out reinforcement. Based on this concept, the bearing capacity ratio can be defined as,

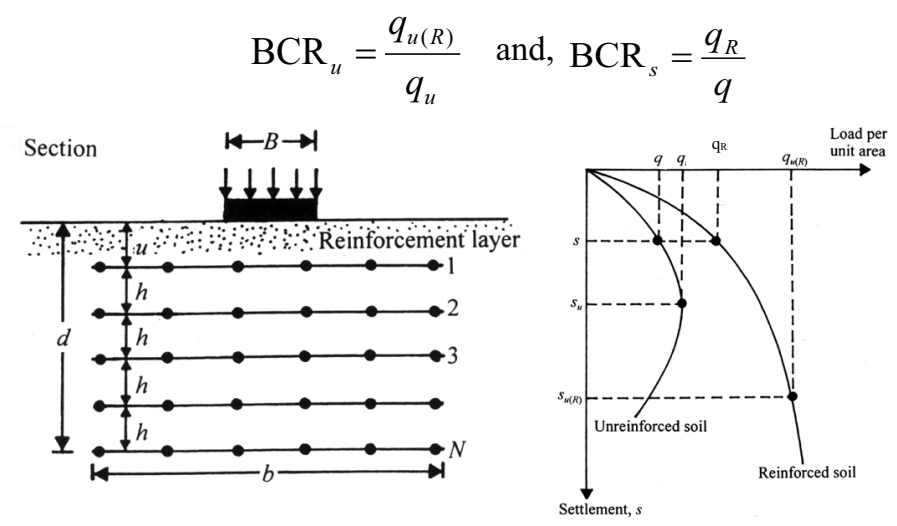

Fig. 1. (a) Geometric parameters of foundation supported by reinforced soil; (b) typical loadsettlement curves for unreinforced and reinforced soil supporting a foundation.

Binquet and Lee $[1,2]$ studied the bearing capacity of shallow foundations resting on reinforced earth. Based on this study, Binquet and Lee proposed failure mechanisms for geogrid-reinforced soils depending on the depth of the reinforcement and number of reinforcement layers as shown in Figs. 2a, 2b, and 2c.

The nature of failure in the soil mass shown in Fig.2a generally occurs when the first layer of reinforcement is located at a depth, $\mathrm{u}$, greater than about $0.67 \mathrm{~B}(\mathrm{~B}=$ width of the foundation). The reinforcement may act in this arrangement as a rough rigid base located at a limited depth. 

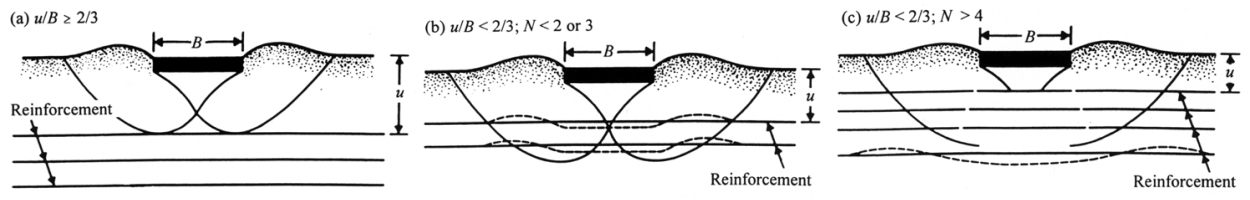

Fig. 2. Three modes of bearing capacity failure of a strip foundation on reinforced earth (after Binquet and Lee, 1975b)

The type of failure shown in Fig. $2 b$ could occur if $\mathrm{u} / \mathrm{B}$ is less than about 0.67 and the number of layers of reinforcement, $\mathrm{N}$, is less than about 2-3. In this type of failure, reinforcement pull-out occurs. According to this study, the most beneficial effect of reinforced earth is obtained when $\mathrm{u} / \mathrm{B}$ is less than about 0.67 and the number of reinforcement layers is greater than 4 but not more than 6-7 (Fig. 2c).

Based on the theory advanced by Binquet and Lee [2], Fig. 3 shows an idealized condition for the development of the failure surface in soil for the condition shown in Fig. 2c. It consists of a central zone-Zone I-immediately below the foundation that settles along with the foundation with the application of load. On each side of Zone I, the soil is pushed outward and upward - this is Zone II. The points A', A", A"', . . and B', B", B"', . . define the limiting lines between Zones I and II, can be obtained by considering the shear stress distribution, $\tau_{\mathrm{xz}}$, in the soil caused by the foundation load. The term $\tau_{\mathrm{xz}}$ refers to the shear stress developed at a depth $\mathrm{d}$ below the foundation at a distance $\mathrm{x}$ measured from the centre line of the foundation. The nature of variation of $\tau_{\mathrm{xz}}$ at any given depth $\mathrm{z}$ is shown by the broken lines in Fig. 3. Points $\mathrm{A}^{\prime}$ and $\mathrm{B}^{\prime}$ refer to the points at which the value of $\tau_{\mathrm{xz}}$ is maximum at $z=z_{1}$. Similarly, $A^{\prime \prime}$ and $B^{\prime \prime}$ refer to the points at which the value of $\tau_{x z}$ is maximum at $\mathrm{z}=\mathrm{z}_{2}$. The distance at which the maximum value of $\tau_{\mathrm{xz}}$ occurs can be given as $\mathrm{x}=\mathrm{X}_{\mathrm{o}}$.

It can be expected that failure in soil reinforced with geo-textile or geogrid layers will be, in general, similar to that described by Binquet and Lee [2] for the case of metal strip reinforcement. However, the magnitude of the ultimate bearing capacity and the allowable bearing capacity for a given level of settlement (and thus $\mathrm{BCR}_{\mathrm{u}}$ and $\mathrm{BCR}_{\mathrm{s}}$ ) will be a function of several factors, such as,

a. The degree of compaction of soil;

b. Relative stiffness of the geogrid or geotextile; and

c. $\mathrm{u} / \mathrm{B}, \mathrm{b} / \mathrm{B}, \mathrm{l} / \mathrm{B}, \mathrm{h} / \mathrm{B}$, and $\mathrm{d} / \mathrm{B}$.

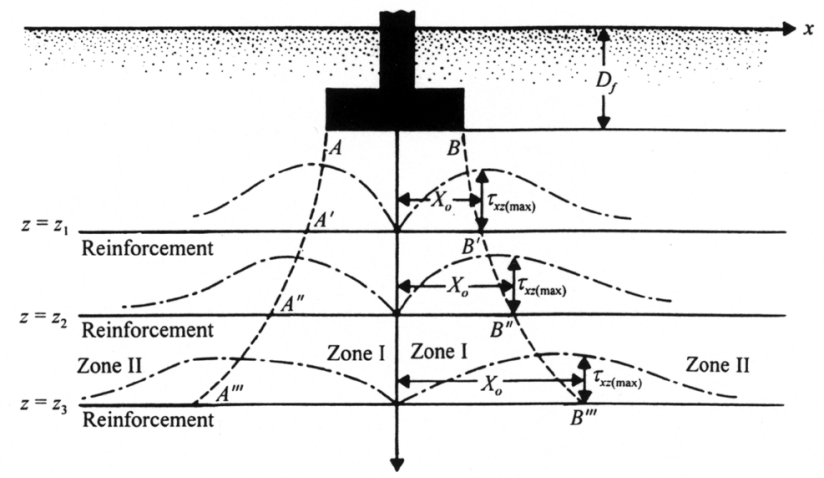

Fig. 3. Failure mechanism under a strip foundation supported by reinforced earth based (after Binquet and Lee (1975b)) 


\section{3 bearing capacity on geogrid-reinforced soil}

\subsection{Geogrid general}

Geogrids are made with high-modulus polymer materials, such as polypropylene and polyethylene through tensile drawing. Geogrids are high tensile stiffness netlike material with large openings called apertures. These apertures enable interlocking with the surrounding soil to reinforce soils. Geogrids are generally of two types: (i) biaxial and (ii) uniaxial. The commercial geogrids currently available for soil reinforcement have a nominal rib thickness of about $0.5-1.5 \mathrm{~mm}$ and junctions of about $2.5-5 \mathrm{~mm}$. The grids used for soil reinforcement usually have apertures that are rectangular or elliptical in shape. The dimensions of the apertures vary from about 25-150 $\mathrm{mm}$. Geogrids are manufactured so that the open areas of the grids are greater than $50 \%$ of the total area. Due to their high tensile stiffness, these geogrids develop reinforcing strength at strain levels as low as $2 \%$.

\subsection{Laboratory experiments on geogrid reinforced soil}

Omar et al. 1993 conducted a series of laboratory scale tests to estimate the bearing capacity for strip footing. Omar et al. 1993 tested an aluminum strip with $76.2 \mathrm{~mm}$ width on geogrid reinforced soils. The tests were conducted in box measuring $1100 \mathrm{~mm}$ length $\times 304$ $\mathrm{mm}$ width $\times 914 \mathrm{~mm}$ depth. Rounded silica sand used in the test has the following properties: dry unit weight of $17.14 \mathrm{kN} / \mathrm{m}^{3}, 70 \%$ relative density and an average peak friction angle of $41^{\circ}$. Omar conducted parametric study varying the following parameters, number of geogrid layers $N$, the depth of first geogrid layer $u$, the width of the geogrid layer $b$, and the vertical distance between two consecutive reinforcement layers, $h$.

\subsubsection{Variation of number of geogrid layers, $N$}

Figure 4 shows results of load per unit area versus settlement of surface model strip foundations $\left(D_{f}=0\right)$ on geogrid-reinforced sand with the following geometrical features $\mathrm{u} / \mathrm{B}=\mathrm{h} / \mathrm{B}=0.33 ; \mathrm{b} / \mathrm{B}=10$. The effect of increasing number of geogrid layers on the bearing capacity of the geogrid reinforced soils is clearly shown in Figure 4.

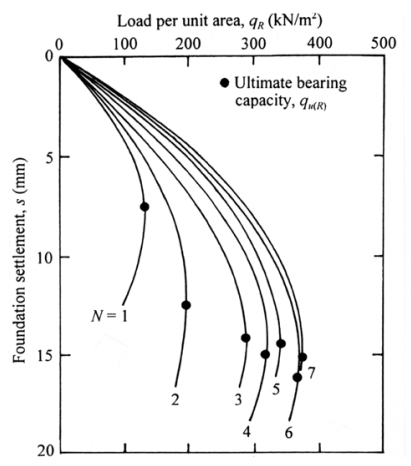

Fig. 4. Load-settlement curves result for a surface strip foundation on geogrid-reinforced sand (after Omar et al., [14]). 


\subsubsection{Variation of $u / B$}

Figure 5 shows typical relationship of normalized depth of the first geogrid layer $(u / b)$ based on laboratory test results of Guido et al. [5], Akinmusuru and Akinbolande [6], Omar et al. [15] and Yetimoglu et al. [16] for bearing capacity tests conducted on surface foundations supported by multi-layered reinforced sand. It appears from these tests results that $(\mathrm{u} / \mathrm{B})_{\max } \approx 0.9$ to 1 . It is also interesting to note that the magnitude of $(\mathrm{u} / \mathrm{B})_{\max }$ was recommended by Binquet and Lee $[1,2]$ to be about 0.67 . Also, laboratory test results suggest that $(\mathrm{u} / \mathrm{B})_{\text {cr }}$ as defined by Fig. 5 is about 0.25 to 0.5 . An analysis of the test results of Schlosser et al. [17] yields a value of $(\mathrm{u} / \mathrm{B})_{\mathrm{cr}} \approx 0.4$. Large-scale model tests of Adams and Collin [18] showed that $(\mathrm{u} / \mathrm{B})_{\mathrm{cr}}$ is approximately 0.25 . Miyazaki and Hirokawa [19] also observed a similar value of $(\mathrm{u} / \mathrm{B}) \mathrm{cr}$ for the case of $\mathrm{N}=1$ (that is, single layer of geogrid reinforcement).

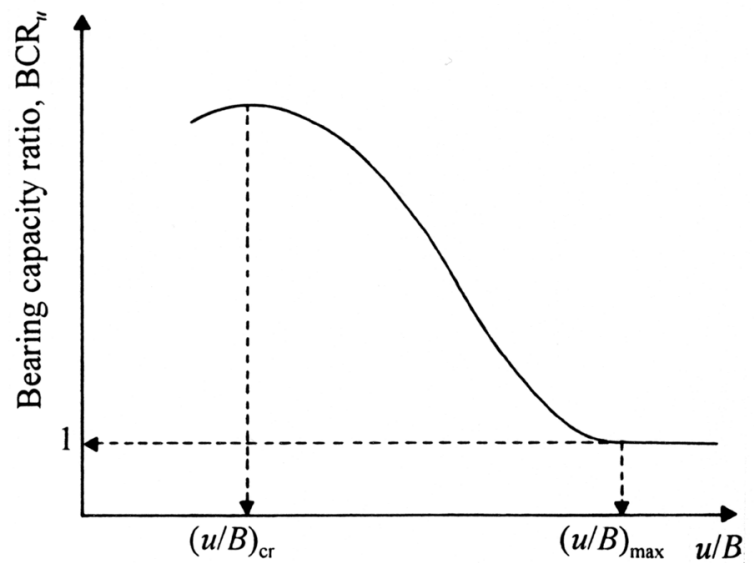

Fig. 5. Typical variation of $B C R_{u}$ with $u / B$ for given values of $b / B, h / B$, and $d / B$.

\subsubsection{Variation of $b / B$ and $l / B$}

Figure 6 shows a relationship between the normalized width of the geogrid reinforcement versus the bearing capacity ratio $\mathrm{BCR}_{\mathrm{u}}$. The figure suggests that the bearing capacity increases with geogrid width increase until a critical value Omar et al. [20] suggested the following empirical relationships for nondimensional parameters of the geo-grid-reinforced soil based on results of laboratory model shown earlier,

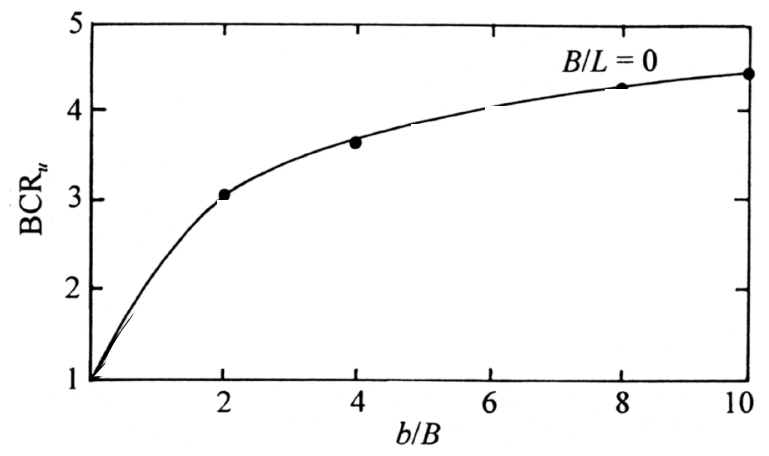

Fig. 6. Variation of $B C R_{u}$ with $b / B$ for strip footing - $u / B=h / B=0.33$ (after Omar et al., 1993c). 


\subsubsection{Relative Stiffness of Geogrids}

It was noted earlier in this paper that the relative stiffness of the geogrid reinforcement may contribute to the magnitude of $\mathrm{BCR}_{\mathrm{u}}$. This will be more noticeable in the case of smallscale laboratory model tests. Guido et al. [5] tested two types of geogrids with different tensile stiffness. The results of bearing capacity ratio $\mathrm{BCR}_{\mathrm{u}}$ versus the normalized width of the geogrid is shown in Figure 7. The results shows a limited increase in bearing capacity with increasing the tensile stiffness of the geogrid. The tensile strength of the geogrids used for Guido et al. [5] tests shown in Fig. 7 were as follows:

\begin{tabular}{lll} 
& \multicolumn{2}{c}{ Tensile strength $(\mathrm{kN} / \mathrm{m})$} \\
\cline { 2 - 3 } Geogrid & $\begin{array}{l}\text { Machine } \\
\text { direction }\end{array}$ & $\begin{array}{l}\text { Cross-machine } \\
\text { direction }\end{array}$ \\
\hline SS1 & 16.8 & 24.8 \\
SS2 & 23.0 & 26.8
\end{tabular}

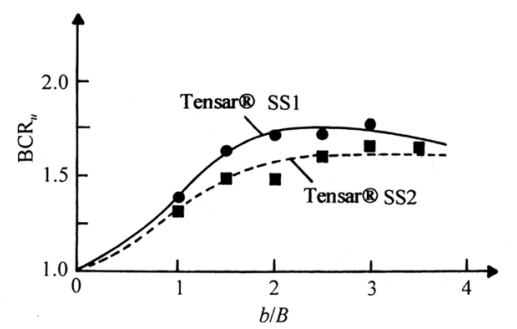

Fig. 7. Variation of $B R_{u}$ with $b / B$ for two geogrids - square foundation; $u / B=0.5 ; h / B=0.25 ; B=$ $0.305 \mathrm{~m} ; \mathrm{N}=3$ (after Guido et al., 1987)

\subsubsection{Scale effects}

Das and Omar [21] conducted several laboratory model tests on surface strip foundations supported by geogrid-reinforced sand in which the foundation width $\mathrm{B}$ was varied. For all tests $\mathrm{u} / \mathrm{B}=\mathrm{h} / \mathrm{B}=0.33, \mathrm{~b} / \mathrm{B}=8$, and $\mathrm{d} / \mathrm{B}=2$. Figure 8 shows the variation of $\mathrm{BCR}_{\mathrm{u}}$ with $\mathrm{B}$ and relative density of sand, $D_{r}$, obtained from the tests. For a given $D_{r}$, the magnitude of $\mathrm{BCR}_{\mathrm{u}}$ de-creases with the increase in $\mathrm{B}$ and reaches an approximate minimum value at $\mathrm{B} \approx$ $150 \mathrm{~mm}$. Figure 8 shows the plots of $\mathrm{BCR}_{u}$ versus $\mathrm{D}_{\mathrm{r}}$ for various values of $\mathrm{B}$. From this figure it appears that $\mathrm{B}$ should be at least $150-180 \mathrm{~mm}$ to obtain $\mathrm{BCR}_{\mathrm{u}}$ from laboratory model tests.

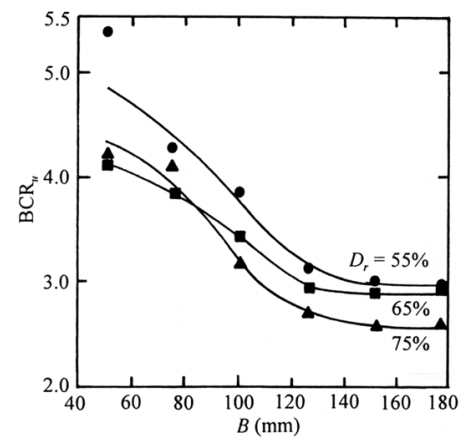

Fig. 8. Variation of $B_{C R}$ with $B$ - strip foundation; Tensar ${ }^{\circledR} B X 1000$ geogrid; $u / B=h / B=0.33$; $\mathrm{b} / \mathrm{B}=8 ; \mathrm{d} / \mathrm{B}=2$ (after Das and Omar, 1994). 


\subsubsection{Bearing capacity for limited settlement}

Shallow foundations are often designed for limited settlement levels and, hence, the magnitude of $\mathrm{BCRu}$ become meaningless for $\mathrm{B}>$ about $1 \mathrm{~m}$. Therefore, it is necessary to determine the bearing capacity ratio at various levels of settlement. The non-dimensional quantity $\mathrm{BCR}_{\mathrm{s}}$ defined by Eq. 2 will be used to define the bearing capacity at specific settlement (s). Omar et al. [22] and Khing et al. [13] conducted limited model studies to determine the relationship between $\mathrm{BCR}_{\mathrm{u}}$ and $\mathrm{BCR}_{\mathrm{s}}$ for strip and square model foundations supported by geogrid-reinforced sand. Figure 9 shows the variation of $\mathrm{BCR}_{\mathrm{u}}$ and $\mathrm{BCR}_{\mathrm{s}}$ with $\mathrm{d} / \mathrm{B}$ (for $\mathrm{s} / \mathrm{s}_{\mathrm{u}}=0.25,0.5$, and 0.75 ).

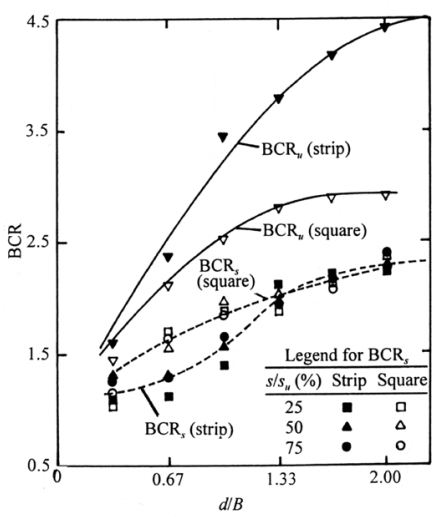

Fig. 9. Variation of $B C R_{u}$ and $B C R_{s}$ with $d / B$ for strip and square foundations on sand (after Omar et al., [22])

It is important to note that $\mathrm{s}_{\mathrm{u}}$ is the settlement of the foundation at ultimate load when supported by unreinforced sand (also see Fig.1). Based on the plots shown in Fig. 9, the following general observations can be made:

a. For a given foundation on geogrid reinforced soil the magnitude of $\mathrm{BCR}_{u}$ is higher than that of $\mathrm{BCR}_{s}$ at $s / s_{u}$ less than or equal to 0.75 .

b. The ratio between the ultimate bearing capacity ratio $\left(\mathrm{BCR}_{\mathrm{u}}\right)$ and bearing capacity ratio at specific settlement $\left(\mathrm{BCR}_{s}\right)$ is about 0.56 for strip foundation.

c. The $\mathrm{BCR}_{s}$ magnitude decreases with decrease of the value of the settlement (s).

\section{Numerical study}

A series of two-dimensional finite element analyses (FEA) of footing resting on geogrid reinforced soil is performed in order to understand the behavior trends of foundations on geogrid reinforced soils. The analysis is performed using the finite element program Plaxis software package (version 2016, 2016).

The geometry of the numerical model was assumed to be 10 times the laboratory model in Omar et al., [22] (the footing width $\mathrm{B}=0.76 \mathrm{~m}$ and thickness, $\mathrm{t}=0.2 \mathrm{~m}$, soil height (sand layer and soft clay layer) is assumed to be $10 \mathrm{~B}$. The software generates the numerical mesh automatically with fifteen node triangle plane strain elements for the soil, and five node beam elements for the footing while five node elastic elements are used for the geogrid elements. 


\subsection{Finite element model}

Hardening soil model available in Plaxis was used to simulate the nonlinear behavior of the sand. Hardening soil model is hyperbolic stress-strain model with limiting states similar to that of Mohr-Coulomb by means of the friction angle $\phi$, cohesion $c$ and the dilatancy angle $\psi$. However, soil stiffness is stress dependent by using three different input stiffness: the triaxial stiffness $\mathrm{E}_{50}$, the triaxial unloading stiffness $\mathrm{E}_{\mathrm{ur}}$ and the oedometer loading tangent stiffness $E_{\text {oed }}$. The foundation was treated as elastic beam elements based with flexural rigidity (EI) and normal stiffness (EA). The interaction between the geogrid and soil is modeled at both sides by means of interface elements, which allow for the specification of a reduced friction compared to assumed friction of the soil. A refined mesh was adopted to minimize the effect of mesh dependency on the finite element modeling of cases involving changes in the number, length, and the location of geogrid layers. In the finite element modeling, the initial stress condition of the slope was established first by applying the gravity force due to soil. A prescribed footing load (beyond the footing ultimate stress) is applied in increments accompanied by iterative analysis up to failure (the iterations stop when failure is reached). The modeled boundary conditions were assumed such that the vertical boundaries are free vertically and constrained horizontally while the bottom horizontal boundary is fully fixed. The general model for the footing on reinforced soil mass, generated mesh, and the boundary conditions are shown in Fig. 10. The model shows the general dimensions of the numerical model with $\mathrm{b}, \mathrm{d}$, $\mathrm{u}$, and $\mathrm{h}$ is as defined in Fig. 1. The width of the strip footing is assumed to be $0.76 \mathrm{~m}$ while the dimensions and number of layers for the geogrid elements are changed to examine the effect of the geogrid configurations on the footing behavior. The hardening soil constitutive parameters are assumed for a dense soil similar to the laboratory testing conducted by Omar et al. [22], As mentioned earlier, Omar et al. used sand with following properties: dry unit weight of 17.14 $\mathrm{kN} / \mathrm{m}^{3}, 70 \%$ relative density and an average peak friction angle of $41^{\circ}$. The dilating angle $\psi$ was assumed to be $10^{\circ}$ and the rest of the soil parameters are shown in Table 1 .

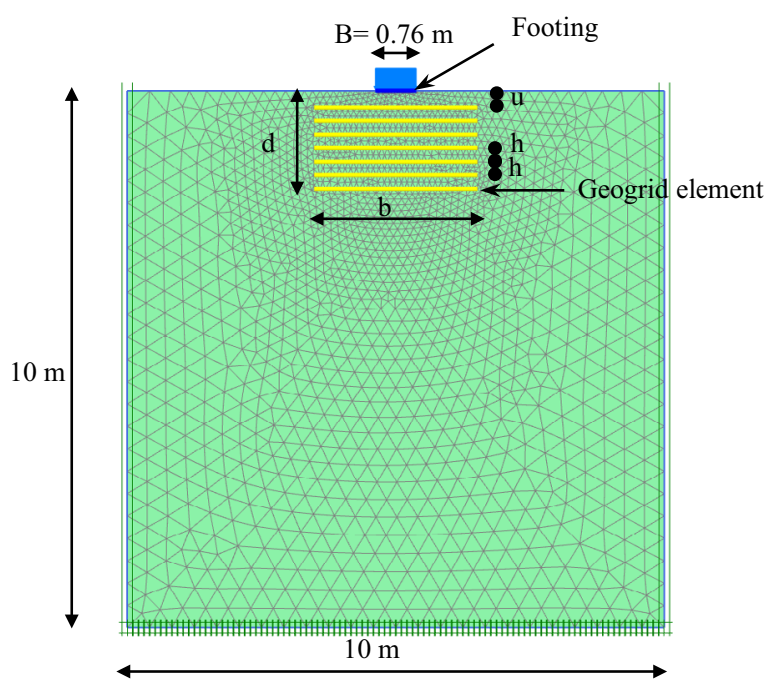

Fig. 10. Prototype of the footing model, generated mesh and boundary conditions. 
Table 1. Finite element model parameters for different parts of the numerical model.

\begin{tabular}{|c|c|c|c|}
\hline Parameter & Sand & Footing & Geogrid \\
\hline Tri-axial stiffness $\mathrm{E}_{50}\left(\mathrm{kN} / \mathrm{m}^{2}\right)$ & 40000 & NA & NA \\
\hline Cohesion $(c)\left(\mathrm{kN} / \mathrm{m}^{2}\right)$ & 0.00 & NA & NA \\
\hline Friction angle $(\varphi)($ degree $)$ & & & NA \\
\hline Dilatancy angle $(\psi)($ degree$)$ & 10.00 & NA & NA \\
\hline Soil Unit Weight $(\gamma)\left(\mathrm{kN} / \mathrm{m}^{2}\right)$ & 17.14 & NA & NA \\
\hline Poisson's ratio $(v)$ & 0.3 & NA & NA \\
\hline Interface reduction factor $\left(\mathrm{R}_{\text {int }}\right)$ & 0.67 & NA & 2000 \\
\hline EA $(\mathrm{kN} / \mathrm{m})$ & NA & 5000000 & $\begin{array}{c}\text { Deform with soil } \\
\text { mesh }\end{array}$ \\
\hline $\mathrm{EI}(\mathrm{kN} \mathrm{m} / \mathrm{m})$ & NA & 8500 & \begin{tabular}{c} 
\\
\hline
\end{tabular} \\
\hline
\end{tabular}

\subsection{Results and discussion}

All the parameters of a control case is tabulated in Table 1. A drained condition is used for all the numerical models. A parametric study was conducted to investigate the effect of different parameters on the bearing capacity of geogrid reinforced soil. For most numerical models, only one parameter is changed and plotted in the x-axis.

\subsubsection{Bearing capacity behavior of unreinforced sand}

A numerical model similar to the numerical model introduced in Fig 10 with no geogrid elements was developed as a control model. The numerical model mesh was generated automatically, though Plaxis automatic mesh scheme, with the same mesh size used for reinforced sand models. A hardening constitutive model with the same properties introduced in Table 1 was used for the control numerical model. Conventional MohrCoulmb linear plastic model with linear stiffness similar to hardening model of 40000 $\mathrm{kN} / \mathrm{m}^{2}$ was used to compare results with the hardening nonlinear model. The footing was loaded until failure was reached. The footing settlement is expressed in non-dimensional form as ratio of footing width $\mathrm{B}(\mathrm{S} / \mathrm{B}, \%)$. Figure 11 shows a comparison of bearing stress $\mathrm{q}$ vs $\mathrm{S} / \mathrm{B}$ curve compared to model with same properties only changing the constitutive model from hardening model to Mohr-Columb model. The friction angle of the model was changed to 30 degrees with zero dilatancy with same hardening model. The results shows a much lower bearing capacity with lower stiffness compared to control model. The MohrColumb model shows a much stiffer response with a higher bearing capacity compared to the control model (hardening non-linear model).

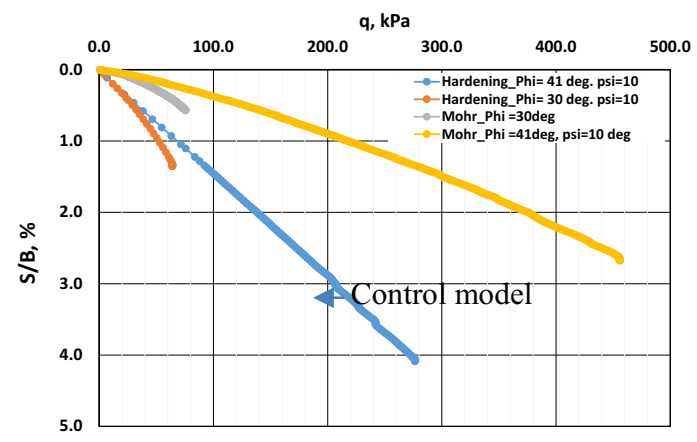

Fig. 11. Variation of footing stress q with S/B percentage for the model footing with different soil constitutive model. 


\subsubsection{Effect of number of geogrid reinforcement layers, $N$}

Two series of numerical studies were conducted in order to study the effect of varying the number of geogrid layers on the bearing capacity of strip footing on geogrid-reinforced soil. In the first study, the control model properties and geometry was used changing only the number of the geogrid with $\mathrm{u} / \mathrm{B}=\mathrm{h} / \mathrm{B}=0.5 ; \mathrm{b} / \mathrm{B}=4$. Figure 12 shows results of load per unit area versus settlement expressed as $\mathrm{S} / \mathrm{B}$ ratio of surface numerical model strip foundations $\left(D_{f}=0\right)$ on geogrid-reinforced sand with the following geometrical features $\mathrm{u} / \mathrm{B}=\mathrm{h} / \mathrm{B}=0.5 ; \mathrm{b} / \mathrm{B}=4$. The effect of increasing number of geogrid layers on the bearing capacity of the geogrid reinforced soils is clearly shown in Figure 12. The increase in the number of geogrid layers results in an increase in the bearing capacity and slight increase in the overall stiffness of the reinforced-sand. Figure 13 shows that the ultimate bearing capacity ratio $\left(\mathrm{BCR}_{\mathrm{u}}\right)$ for the soil increases with the number of grid layers, N. The $\mathrm{BCR}_{\mathrm{u}}$ reaches value of 6 when the number of geogrid layers reaches seven layers. Which means that numerical model predicts a significant increase in ultimate bearing capacity of geogrid reinforced soil with the increase of number of geogrid layers. Figure 13 shows also a relationship of the $B C R_{s}$ at a settlement ratio $(\mathrm{S} / \mathrm{B} \%)$ about $3.3 \%$ corresponding to a settlement of about $2.5 \mathrm{~cm}$ versus the increase in the number of the geogrid layers. The figure shows that the value of the BCRs reached a value of approximately 1.5 for seven layers of geogrid reinforcement compared to a value of 6 for BCRu for the same number of geogrid layers. This value is much less than values reported in the literature for BCRs. Omar et al., [22] reported values of BCRs up to about 2.5 for $\mathrm{S} / \mathrm{Su}=25 \%$. Moreover, the increase in the number of geogrid layers does not have a significant effect on the BCRs. This is attributed to the fact that the calculated load per unit area versus settlement for reinforced soils did not show a significant increase in stiffness compared to unreinforced soils especially at low settlement. The tangent modulus of the reinforced soil did not significantly improve with the soil reinforcement. This is why the calculated $\mathrm{BCR}_{\mathrm{S}}$ did not show significant increase with the increase in the number of the reinforcement layers. This does not agree with laboratory results reported by Omar et al., [22]. This is may be attributed to that numerical model did not capture the effect of pre-tention effect in the geogrid layers during compaction.

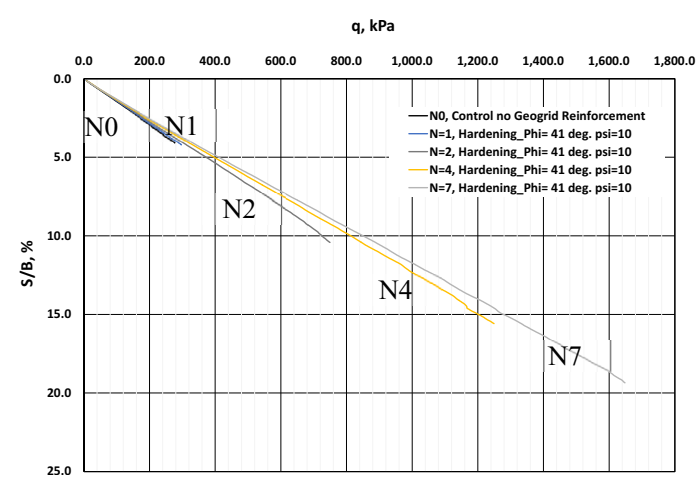

Fig. 12. Load-settlement curves results for a numerical model of strip footing on geogrid-reinforced sand with variation of number of geogrid layers. 


\subsubsection{Effect of constitutive model on the behavior of geogrid-reinforced soil}

The effect of the constitutive model on the calculated behavior of the geogridreinforcement soil numerical model was investigated. For this study a parametric study was conducted using control model with the same geometry and properties shown in Fig.10 changing only the constitutive model from hardening model to the conventional MohrCoulomb model. The Mohr- Coulomb constitutive model is elastic perfectly plastic model compared while the hardening model is nonlinear model. The Mohr-Columb model was used with the same properties similar to the base model with elastic modulus of 40000 $\mathrm{kN} / \mathrm{m} 2$ with a friction angle of $41^{\circ}$ and a dilatancy angle of $10^{\circ}$. In the parametric study, the number of geogrid layers was changed while keeping the rest of the parameters constant. Figure 13 shows that for a soil modeled as Mohr-Coulomb model the increase in number geogrid layers the calculated BCR did not show any significant increase with the increase of the number of Geogrid layers.

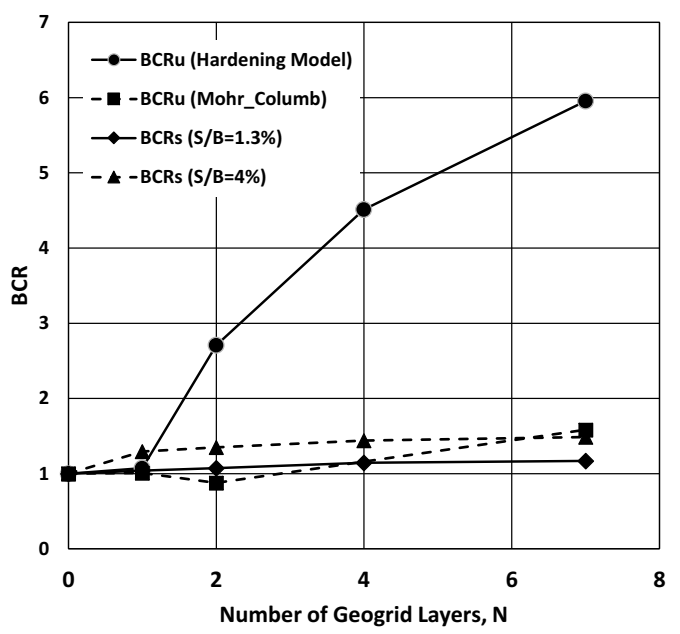

Fig. 13. Variation of $\mathrm{BCR}_{\mathrm{u}}$ and $\mathrm{BCR}$ s with number of georid layers.

\subsubsection{Effect of the geogrid stiffness on the bearing capacity of the geogrid- reinforced soil}

A study was conducted to investigate the effect of the geogrid stiffness on the behavior of the geogrid-reinforced soil. In this study, control model was used with the following properties $\mathrm{u} / \mathrm{B}=0.5 ; \mathrm{b} / \mathrm{B}=4$ with only one layer of reinforcement. The modulus of the geogrid EA was changed keeping all the other factors constant. A relationship was plotted between the geogrid modulus EA and $\mathrm{BCR}_{\mathrm{u}}$ shown in Figure 14. Figure 14 shows that increasing the geogrid modulus one order of magnitude increased the $\mathrm{BCR}_{\mathrm{u}}$ from 1.07 to 1.62. However, increasing the stiffness one more order of magnitude did not significantly increase the $\mathrm{BCR}_{\mathrm{u}}$. 


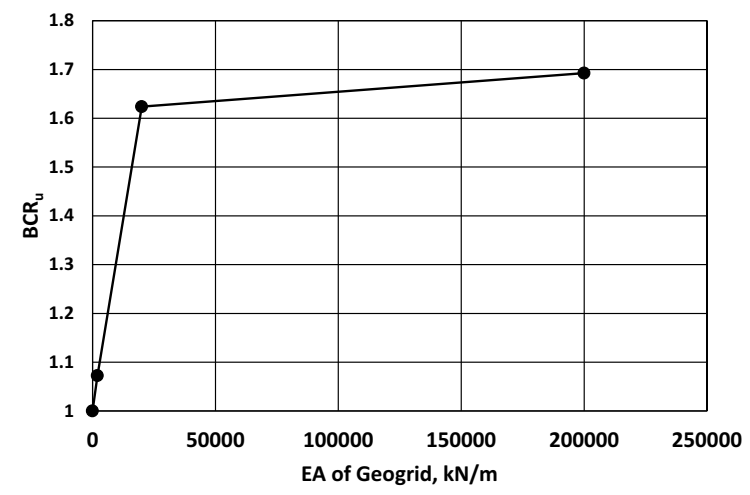

Fig. 14. Variation of $B C R_{u}$ with geogrid stiffness.

4.2.1 Effect of the geogrid width (b) on the bearing capacity of the geogridreinforced soil

A study was conducted to investigate the effect of the geogrid width on the behavior of the geogrid-reinforced soil. In this study, control model was used with the following properties $\mathrm{u} / \mathrm{B}=\mathrm{h} / \mathrm{B}=0.5 ; \mathrm{b} / \mathrm{B}=4, \mathrm{~N}=7$ with seven layers of reinforcement. The width of the reinforcement was changed while keeping the rest of the parameters constant. Figure 15 shows a relationship between the $\mathrm{BCR}_{\mathrm{u}}$ with the geogrid width. In the figure, the $\mathrm{BCR}_{\mathrm{u}}$ increases with the increase of the geogrid width until the width reaches a value of about $3 \mathrm{~B}$ the increase in width become insignificant in terms of bearing capacity increase.

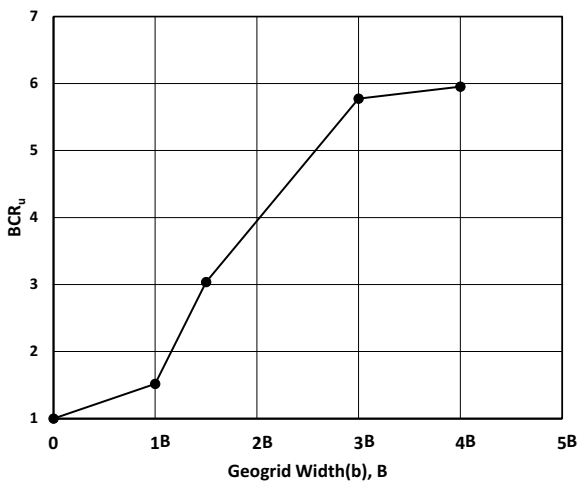

Fig. 15. Variation of $\mathrm{BCR}_{\mathrm{u}}$ with width of the geogrid (b).

\section{Conclusions and future work}

The bearing capacity behavior of strip footing on geogrid reinforced soil was investigated. The effect of geogrid reinforcement on the sand bearing capacity was investigated numerically. Based on the results of the investigation the following conclusions can be drawn: 
1- A significant increase in soil bearing capacity with geogrid reinforcement in the soil was shown experimentally and numerically.

2-Hardening non-linear constitutive model is suitable to capture the main characteristics of the geogrid reinforced soils. However, Mohr-Columb is not a suitable constitutive model to capture the main characteristics for geogridreinforced soil.

3- The numerical model was not able to capture the behavior of the geogrid-reinforced soil at low settlement.

4- An agreement between the experimental and numerical results on the general trend of critical parameters on the geogrid-reinforced soil bearing capacity. In all cases, $\mathrm{BCR}_{\mathrm{S}}$ calculated from the numerical analysis appears to be smaller than obtained from the experimental results.

\section{References}

1. Binquet, J., \& Lee, K.L. Bearing capacity tests on reinforced earth mass. Journal of Geotechnical Engineering Division, ASCE, 101(12), 1241-55 (1975a).

2. Binquet, J., \& Lee, K.L. Bearing capacity analysis of reinforced earth slabs. Journal of Geotechnical Engineering Division, ASCE, 101(12), 1257-76 (1975b).

3. Guido, V.A., Biesiadecki, G.I., \& Sullivan, M.J. Bearing capacity of a geotextile reinforced foundation. Proceedings of the XI International Conference on Soil Mechanics and Foundation Engineering, 3, A.A. Balkema, The Netherlands, 1777-80 (1985).

4. Guido, V.A., Chang, D.K., \& Sweeny, M.A. Comparison of geogrid and geotextile reinforced slabs. Canadian Geotechnical Journal, 23, 435-40 (1986)..

5. Guido, V.A., Knueppel, J.D., \& Sweeny, M.A. Plate load tests on geogrid-reinforced earth slabs. Proceedings of Geosynthetics '87, 216-25 (1987).

6. Akinmusuru, J.O., \& Akinbolande, J.A. Stability of loaded footings on reinforced soil. Journal of Geotechnical Engineering Division, ASCE, 107, 819-27. (1981).

7. Fragaszy, R.J., \& Lawton, E.C. Bearing capacity of reinforced sand subgrades. Journal of Geotechnical Engineering Division, ASCE, 110, 1500-07. (1984).

8. Fragaszy, R.J., Lawton, E.C., \& Asgharzadel-Fozi, Z. Bearing capacity of reinforced sand. Proceedings of the VIII European Conference on Soil Mechanics and Foundation Engineering, Helsinki, 1, 51-84. (1983).

9. Huang, C.C., \& Hong, L.K. Ultimate bearing capacity and settlement of footings on reinforced sandy ground. Soils and Foundations, 49(5), 65-73. (2000).

10. Huang, C.C., \& Meng, F.Y. Deep footing and wide-slab effects on reinforced sandy ground. Journal of Geotechnical and Geoenvironmental Engineering, ASCE, 123(1), 30-36. (1997).

11. Huang, C.C., \& Tatsuoka, F. Prediction of bearing capacity in level sandy ground reinforced with strip reinforcement. Proceedings of the International Geotechnical Symposium on Theory and Practice of Earth Reinforcement, Fukuoka, Japan, A.A. Balkema, The Netherlands, 191-96. (1988).

12. Huang, C.C., \& Tatsuoka, F. Bearing capacity of reinforced horizontal sandy ground. Geotextiles and Geomembranes, 9, 51-82. (1990).

13. Khing, K.H., Das, B.M., Puri, V.K., Cook, E.E., \& Yen, S.C. The bearing capacity of a strip foundation on geogrid-reinforced sand. Geotextiles and Geomembranes, 12(4), 351-61. (1993). 
14. Omar, M.T., Das, B.M., Puri, V.K., \& Yen, S.C. Ultimate bearing capacity of shallow foundations on sand with geogrid reinforcement. Canadian Geotechnical Journal, 30(3), 545-59. (1993a).

15. Omar, M.T., Das, B.M., Puri, V.K., Yen, S.C., \& Wright, M.A. A comparison of the ultimate bearing capacity of square and strip foundations on geogrid-reinforced sand. Proceedings of Numerical Models in Geomechanics, A.A. Balkema, 967-76. (1992).

16. Yetimoglu, T., Wu, J.T.H., \& Saglamer, A. Bearing capacity of rectangular footings on geogrid-reinforced sand. Journal of Geotechnical Engineering, ASCE, 120(12), 208399. (1994)

17. Schlosser, F., Jacobsen, H.M., \& Juran I. Soil reinforcement. General Report, VIII European Conference on Soil Mechanics and Foundation Engineering, Balkema, Helsinki, 83-103. (1983).

18. Adams, M.T., \& Collin, J.C. Large model spread footing load tests on geogridreinforced soil foundations. Journal of Geotechnical and Geoenvironmental Engineering, 123(1), 66-72. (1997).

19. Miyazaki, K., \& Hirokawa, F. Fundamental study of reinforcement of sand layer in model test. Proceedings of the International Symposium on Earth Reinforcement Practice, Fukuoka, Japan, 1, 647-52. (1992).

20. Omar, M.T., Das, B.M., Puri, V.K., Yen, S.C., \& Cook. E.E Ultimate bearing capacity of rectangular foundations on geogrid-reinforced sand. Geotechnical Testing Journal, ASTM, 16(2), 246-52. (1993c).

21. Das, B.M., \& Omar, M. T. The effect of foundation width on model tests for the bearing capacity of sand with geogrid reinforcement. Geotechnical and Geological Engineering, 11, 135-41. (1994).

22. Omar, M.T., Das, B.M., Puri, V.K., Yen, S.C., \& Cook. E.E. Shallow foundations on geogrid-reinforced sand. National Academy of Sciences, Washington, D.C., Transportation Research Record 1414, 59-64 (1993b). 